\title{
NFkB activation promotes immune activation in HTLV-I-associated myelopathy / tropical spastic paraparesis
}

\author{
Matthew McCormick', Unsong Oh', Dibyadeep Datta', Richard Turner', Kathryn Bobb², Dileep Monie², \\ Drago R Sliskovic ${ }^{3}$, Jie Zhang' ${ }^{2}$, Jeffrey Meshulam², Steven Jacobson ${ }^{1 *}$ \\ From 15th International Conference on Human Retroviruses: HTLV and Related Viruses \\ Leuven and Gembloux, Belgium. 5-8 June 2011
}

Evidence suggests that HTLV-I-induced immune activation plays a key role in the pathogenesis of HAM/TSP. The HTLV-I-encoded transactivating protein Tax is known to activate nuclear factor kappa B (NFkB), a key host signaling pathway regulating immune response, but the contribution of the NFkB pathway to the immune activation associated with HAM/TSP has yet to be fully defined. We examined NFkB activation in peripheralblood mononuclear cells (PBMC) from subjects with HAM/TSP, and tested the effect of NFkB inhibition on key ex vivo correlates of immune activation in HAM/ TSP.

We examined the role of NFkB activation during immune activation associated with HAM/TSP by using small molecule NFkB inhibitors, including a newly developed selective inhibitor of NFkB, PBS-1086.

NFkB activation was assessed in peripheral-blood mononuclear cells (PBMC) from subjects with HAM/ TSP and in healthy donors (HD). Nuclear translocation of the NFkB RelA was significantly higher in PBMC from subjects with HAM/TSP compared to HD $(\mathrm{p}=0.032)$ following short-term $(20 \mathrm{~h})$ culture, indicating increased activation of the NFkB pathway in HAM/TSP. Treatment with the small molecule inhibitor PBS-1086 reduced NFkB activation $(\mathrm{p}<0.01)$. PBS-1086 reduced expression of CD25 and CD69 in HAM/TSP PBMC as well as phosphorylation of STAT5 in a dose-dependent manner $(\mathrm{p}<0.01$ for all). PBS-1086 also inhibited spontaneous lymphoproliferation of HAM/TSP PBMC in a dose-dependent manner $(\mathrm{p}=0.0286)$. PBS-1086 treatment

\footnotetext{
* Correspondence: jacobsons@ninds.nih.gov

${ }^{1}$ Neuroimmunology Branch, National Institute of Neurological Diseases and

Stroke, National Institutes of Health, Bethesda, MD, USA

Full list of author information is available at the end of the article
}

resulted in a mean proviral load reduction of $20 \%$ compared to untreated PBMC in a $72 \mathrm{~h}$ culture

These results indicate that NFkB activation plays a critical upstream role in the immune activation associated with HAM/TSP, and identify the NFkB pathway as a potential therapeutic target for immune modulation in $\mathrm{HAM} / \mathrm{TSP}$.

\section{Author details}

${ }^{1}$ Neuroimmunology Branch, National Institute of Neurological Diseases and Stroke, National Institutes of Health, Bethesda, MD, USA. ${ }^{2}$ Profectus Biosciences, Inc., Baltimore, MD, USA. ${ }^{3}$ IDSC, Chelsea, MI, 48118, USA.

\section{Published: 6 June 2011}

\section{doi:10.1186/1742-4690-8-S1-A117}

Cite this article as: McCormick et al:: NFkB activation promotes immune activation in HTLV-I-associated myelopathy / tropical spastic paraparesis. Retrovirology 2011 8(Suppl 1):A117.

Submit your next manuscript to BioMed Central and take full advantage of:

- Convenient online submission

- Thorough peer review

- No space constraints or color figure charges

- Immediate publication on acceptance

- Inclusion in PubMed, CAS, Scopus and Google Scholar

- Research which is freely available for redistribution 